\title{
Article \\ Evaluating Environmental Enrichment Methods in Three Zoo-Housed Varanidae Lizard Species
}

\author{
James O. Waterman ${ }^{1} \oplus$, Rachel McNally ${ }^{1,2}$, Daniel Harrold ${ }^{1}$, Matthew Cook $^{1}$, Gerardo Garcia ${ }^{1}$, \\ Andrea L. Fidgett ${ }^{1,3}$ and Lisa Holmes $1, *(D)$ \\ 1 Chester Zoo, Upton-by-Chester, Chester CH2 1LH, UK; j.waterman@chesterzoo.org (J.O.W.); \\ rachelmcnally@outlook.com (R.M.); dh16450.2016@my.bristol.ac.uk (D.H.); m.cook@chesterzoo.org (M.C.); \\ g.garcia@chesterzoo.org (G.G.); AFIdgett@sdzwa.org (A.L.F.) \\ 2 Faculty of Biology, Medicine and Health, University of Manchester, Manchester M13 9PL, UK \\ 3 San Diego Zoo, Zoo Wildlife Alliance, San Diego, CA 92101, USA \\ * Correspondence: 1.holmes@chesterzoo.org
}

check for updates

Citation: Waterman, J.O.; McNally, R.; Harrold, D.; Cook, M.; Garcia, G.; Fidgett, A.L.; Holmes, L. Evaluating Environmental Enrichment Methods in Three Zoo-Housed Varanidae Lizard Species. J. Zool. Bot. Gard. 2021, 2, 716-727. https://doi.org/ $10.3390 /$ jzbg2040051

Academic Editors: Kris Descovich, Caralyn Kemp and Jessica Rendle

Received: 1 November 2021

Accepted: 26 November 2021

Published: 14 December 2021

Publisher's Note: MDPI stays neutral with regard to jurisdictional claims in published maps and institutional affiliations.

Copyright: (c) 2021 by the authors. Licensee MDPI, Basel, Switzerland. This article is an open access article distributed under the terms and conditions of the Creative Commons Attribution (CC BY) license (https:/ / creativecommons.org/licenses/by/ $4.0 /)$.

\begin{abstract}
Environmental enrichment has been shown to enhance the behavioural repertoire and reduce the occurrence of abnormal behaviours, particularly in zoo-housed mammals. However, evidence of its effectiveness in reptiles is lacking. Previously, it was believed that reptiles lacked the cognitive sophistication to benefit from enrichment provision, but studies have demonstrated instances of improved longevity, physical condition and problem-solving behaviour as a result of enhancing husbandry routines. In this study, we evaluate the effectiveness of food- and scent-based enrichment for three varanid species (Komodo dragon, emerald tree monitor lizard and crocodile monitor). Scent piles, scent trails and hanging feeders resulted in a significant increase in exploratory behaviour, with engagement diminishing $\leq 330 \mathrm{~min}$ post provision. The provision of food- versus scent-based enrichment did not result in differences in enrichment engagement across the three species, suggesting that scent is just as effective in increasing natural behaviours. Enhancing the environment in which zoo animals reside is important for their health and wellbeing and also provides visitors with the opportunity to observe naturalistic behaviours. For little known and understudied species such as varanids, evidence of successful (and even unsuccessful) husbandry and management practice is vital for advancing best practice in the zoo industry.
\end{abstract}

Keywords: behavior; environmental enrichment; evidence-based; husbandry; reptile; lizard; welfare; zoo

\section{Introduction}

Environmental enrichment (referred to as enrichment hereafter) is used to improve the health and welfare of species managed ex situ, one desired outcome of which is the broadening of an individual's behavioural repertoire [1]. Reptile enrichment methods have historically been based on the anecdotal evidence of caregivers, often drawn from experience with a limited group of individuals [2,3]. As such, there is limited information describing the impacts (positive and negative) of these methods [4-7], including the extent to which different types of enrichment affect behaviour, and the longevity of these effects [8-10]. However responsible, modern collections require robust, quantitative evidence on which to base husbandry decisions; despite an increasing focus on herptile enrichment, this is still lacking for reptiles $[1,3,6]$.

Two key points may account for this gap in our knowledge: (1) evaluating the welfare of reptiles is challenging [6] and/or (2) the cognitive sophistication of non-avian reptiles is often under-estimated (particularly compared to that of mammals and birds [8,11,12]). However, there is clear evidence that many captive squamates provided with enrichment display unexpected problem-solving skills, enhanced behavioural development and plas- 
ticity, and reduced stereotypies, as well as greater longevity, increased breeding success, and improved body condition [8,13-17].

Here, we examine the behavioural responses (exploratory behavior and engagement with enrichment objects) to enrichment of three Southeast Asian varanid species held at Chester Zoo, UK: Komodo dragons (Varanus komodoensis), emerald tree monitors (V. prasinus) and crocodile monitors (V. salvadorii). Varanid (monitor) lizards (Varanus; Merrem, 1820) are endemic to a variety of habitats in Afro-Eurasia [5] and common within zoological collections. Komodo dragons are largely terrestrial, inhabiting woodland and dry savannah habitats of the Eastern Indonesian islands. Emerald tree monitors and crocodile monitors are largely arboreal, inhabiting rainforests and mangroves on Papua [18]. All three species are predominantly carnivorous, intelligent, occupy large territories and have a high metabolic rate compared to other reptiles [16,18-20].

There are five main ways in which environmental enrichment may be provided: by (1) creating and managing a dynamic habitat, (2) encouraging social interactions between individuals, (3) encouraging foraging, (4) introducing novel objects and (5) training [21]. These methods aim to increase behavioural diversity, reduce abnormal behaviours, increase the range of natural behaviours demonstrated, increase the positive use of the environment, and increase the animal's ability to cope with challenges in a more natural way [22]. We focus here on whether, and to what extent, the provision of a variety of enrichment items encourages exploratory foraging behaviour and/or direct item engagement (see Table 1 for descriptions of enrichment items and Table 2 for behavioural definitions). The study individuals are routinely provided with (predominantly food-based) enrichment, but no long-term monitoring of its efficacy has been carried out. Additionally, because olfactory stimuli play an important role in foraging, mating and social interactions in these species [18], a mixture of food- and scent-based enrichment items was used for this investigation.

Table 1. Description of enrichment conditions and the species to which they were presented.

\begin{tabular}{|c|c|c|}
\hline $\begin{array}{l}\text { Enrichment } \\
\text { Condition }\end{array}$ & Description & $\begin{array}{l}\text { Species } \\
\text { Sampled }\end{array}$ \\
\hline \multirow{3}{*}{ Control } & \multirow{3}{*}{ Keeper entered enclosure as per normal husbandry routine for two minutes. } & V. komodoensis \\
\hline & & $V \cdot$ prasinus \\
\hline & & V. salvadorii \\
\hline \multirow{2}{*}{ Furnishings } & \multirow{2}{*}{$\begin{array}{l}\text { Bedding and enclosure furniture from four mammalian exhibits: Congo buffalo (Syncerus } \\
\text { caffer nanus) bedding; red river hog (Potamochoerus porcus) browse logs; white-faced saki } \\
\text { monkey (Pithecia pithecia) enclosure logs; mixed bedding from Bovidae species. }\end{array}$} & V. komodoensis \\
\hline & & V. salvadorii \\
\hline Food (ground) & Hollowed log feeders filled with black crickets (Gryllus sp.) on enclosure floor. & V. prasinus \\
\hline Food (suspended) & $\begin{array}{l}\text { Hollowed log feeders filled with black crickets (Gryllus sp.) suspended on } \\
\text { enclosure furniture. }\end{array}$ & $V$. prasinus \\
\hline Scent (trail—food) & $\begin{array}{l}\text { Blended food items (quail eggs, quail feathers, chicken eggs) spread throughout } \\
\text { the enclosure. } \\
\text { Food items (quail meat, day-old chickens) were also placed along the scent trail. }\end{array}$ & V. salvadorii \\
\hline \multirow{3}{*}{ Scent (trail) } & \multirow{3}{*}{$\begin{array}{l}\text { Liquids spread throughout the enclosure (blood-water solution, fish defrosting water, } \\
\text { blended pinkie mice, blended quail eggs and feathers). }\end{array}$} & $V$. komodoensis \\
\hline & & V.prasinus \\
\hline & & V. salvadorii \\
\hline Scent (pile) & $\begin{array}{l}\text { A blood-water solution spread throughout the exhibit (within leaf/litter, on logs, buried } \\
\text { in substrate surface, as a frozen solution on ground). }\end{array}$ & V. komodoensis \\
\hline
\end{tabular}


Table 2. Varanid lizard ethogram.

\begin{tabular}{|c|c|}
\hline Behaviour & Description \\
\hline Bask & Individual stationary underneath a heat/UV lamp for a minimum of five seconds. \\
\hline Rest & Individual stationary (not under a heat/UV lamp) for a minimum of five seconds. \\
\hline Explore & $\begin{array}{l}\text { Relaxed interest/awareness in proximate or novel objects, relaxed visual explorations. Calm chemical } \\
\text { sampling of surrounding, e.g., smelling or tasting objects or air (tongue-flicking). Individual moves } \\
\text { more than half a body length from its starting position. }\end{array}$ \\
\hline Feed & $\begin{array}{l}\text { Consumption of food items, including holding food in mouth, chewing and swallowing. Feeding was } \\
\text { considered finished after swallowing had stopped. }\end{array}$ \\
\hline Social & Touching, vocalising and/or signalling to a conspecific. \\
\hline $\begin{array}{l}\text { Enrichment engagement } \\
\text { (interest) }\end{array}$ & $\begin{array}{l}\text { Rapid chemical sampling of surrounding, e.g., smelling or tasting objects or air (tongue-flicking). } \\
\text { Individual moves (more than half a body length from its starting position) directly towards and/or } \\
\text { stares directly at enrichment item. }\end{array}$ \\
\hline $\begin{array}{l}\text { Enrichment engagement } \\
\text { (use) }\end{array}$ & $\begin{array}{l}\text { Direct manipulation of enrichment item, including attempts to reach the item and/or active following } \\
\text { of scent trails. Where live food was presented, included chasing food items. }\end{array}$ \\
\hline
\end{tabular}

We predicted (P.1) that the provision of enrichment would increase exploratory behaviour, compared to control trials and (P.2) that the magnitude of any changes in exploratory behaviour would differ by enrichment type. We also predicted (P.3) that engagement with enrichment would differ by item type and (P.4) that engagement would diminish over time as the stimulating effect of novelty wore off. Finally, we predicted (P.5) that individuals would engage with food-based enrichment items for longer than with scent-based items. We made no predictions about species-specific responses to enrichment or enrichment type, because the data were too sparse (see Section 2.3) to support the inclusion of meaningful three-way interactions. However, we include raw data plots to highlight species-specific responses to enrichment provision and/or type.

\section{Materials and Methods}

\subsection{Study Individuals and Housing}

Five individuals from three species were studied: V. komodoensis (one male and one female, both 4 years old). During the enrichment trials, the male was housed in an onshow mixed-species exhibit $(8.0 \times 14.0 \times 11.5 \mathrm{~m})$ with Java sparrows (Lonchura oryzivora) with an average ambient temperature of $26-28^{\circ} \mathrm{C}$. The female was housed singly in an off-show exhibit $(4.0 \times 3.3 \times 2.5 \mathrm{~m})$ with an ambient temperature range of $22-28{ }^{\circ} \mathrm{C}$ and infra-red heaters providing basking spots with a temperature range of $27-44{ }^{\circ} \mathrm{C}$; $V$. prasinus (one male and one female, 15 and 8 years old, respectively) was housed in a single-species enclosure $(2.0 \times 1.5 \times 2.5 \mathrm{~m})$ with an ambient temperature range of $20-28{ }^{\circ} \mathrm{C}$, a radiant panel heater and $160 \mathrm{w}$ solar raptor spot lamps to provide basking spots with a temperature range of $30-35{ }^{\circ} \mathrm{C} ; \mathrm{V}$. salvadorii (a single female, 11 years old) was housed in a single-species enclosure $(5.5 \times 2.0 \times 4.0 \mathrm{~m})$ with an ambient temperature range of $21-27^{\circ} \mathrm{C}$, a ceramic panel and infra-red heaters providing basking spots with a temperature range of $33-35^{\circ} \mathrm{C}$. All individuals were assessed to be in good clinical health prior to and throughout sampling.

\subsection{Testing Protocol}

Following a three-week pilot study in December 2014, the study individuals were presented with a randomized series of six enrichment conditions (Table 1), plus a control, over the course of 16 weeks (8 January 2015 through 6 May 2015). Different enrichment conditions were only presented once to each species, but not all species were presented with all possible enrichment types (see Table 1); the control was presented four times to each species. Once a week, each species was observed on one day, for a total of $80 \mathrm{~min}$, split into four 20 min blocks: (1) pre-enrichment, (2) during-enrichment, (3) post-enrichment 
1 , and (4) post-enrichment 2. Blocks one and two were contiguous, spanning the $40 \mathrm{~min}$ prior to and following the introduction of the enrichment/control item (at approximately $1100 \mathrm{~h}$ ). To examine the longevity of the enrichment effect, blocks 3 and 4 began at random times, 30-150 min and 151-330 min, respectively, after the introduction of the enrichment/control. Control trials were time-matched with enrichment trials to control for potential diel effects. Because captive animals often respond to known keepers and/or their distinctive uniformed appearance, the observer $(\mathrm{N}=1)$ wore 'normal' clothing and carried out observations from the public viewing windows.

\subsection{Data Collection}

Following an adapted ethogram [23,24] (Table 2), behavioural data were collected (with pen and paper) using continuous all-occurrences focal animal sampling [25]. This yielded a total of $94 \mathrm{~h}$ and $24 \mathrm{~min}$ of data over 47 observation days and 71 observation sessions.

\subsection{Data Preparation}

To prepare our data for analysis, we removed any $(20 \mathrm{~min})$ observation blocks in which the study individuals were out of sight for the entire duration $(\mathrm{N}=24)$. In order to compare the effect of food- and scent-based enrichment, we collapsed enrichment conditions into food-based (Food (ground), Food (suspended), Scent (trail-food)) and scentbased (Furnishings, Scent (trail), Scent (pile)). For our response variables, we calculated the proportion (expressed as a percentage throughout) of observation time individuals spent in exploratory and enrichment engagement behaviour (see Table 2). Beta regression is the most appropriate way to model proportion data (described in Section 2.5), but these models cannot handle values of exactly zero or one. Therefore, we compressed the range of the data according to the following equation: $p^{\circ}=(p(n-1)+1 / 2) / n$, where $p$ is the original proportion, and $n$ is the sample size [26].

\subsection{Statistical Analysis}

All analyses were carried out using the software R, version 4.1.0 [27]. We used the package 'glmmTMB' [28] to fit three Beta GLMMs (Generalized Linear Mixed Models) with logit links. The Beta distribution is typically used to model continuous proportion data, and the logit link function ensures positive fitted values that range from 0 to 1 [29]. Proportion data are by definition limited to numerical values between, and including, 0 and 1 , and their variance is rarely constant across the range of the predictor(s). As such, they typically violate two important assumptions of standard statistical techniques (normality of errors and constant variance) [30]. This makes analysis using familiar techniques (such as linear regression and ANOVA and their extensions) inappropriate. Transformations are often applied to proportion data, so that linear models can be used [31], but these result in biased estimates and difficulties in interpretation. However, after the appropriate adjustment (detailed above), beta regression provides a robust and easily interpretable approach to modelling proportion data.

We used a full model approach throughout, and model fit and assumptions were verified by plotting residuals versus fitted values with the package 'DHARMa' [32]. We determined the significance of the fixed effects using likelihood ratio tests. We fitted full and restricted models (models in which the parameter of interest, the fixed effect, are withheld, i.e., fixed to 0) and based test statistics on comparisons of the full model with the restricted models. The significance of the likelihood ratio test statistic is calculated using a chi-squared distribution with the appropriate degrees of freedom. Post-hoc tests were carried out using Tukey's HSD (honestly significant difference) tests, with the package 'emmeans' [33]. All statistical tests were two-tailed with $\alpha$ set to 0.05 .

All models included the same control variables: sex (factor with two levels: female, male) and days since last feed (continuous numeric variable: range 0-31). Days since last feed was scaled and centred prior to analysis. To incorporate the dependency among observations of the same individuals, of the same species, across the four observation 
blocks, all models included the same random effects structure; trial nested in individual, nested in species was used as a random intercept.

\subsubsection{Model 1: Effect of Enrichment on Exploratory Behaviour}

To model the proportion of time that individuals spent in exploratory behaviour as a function of enrichment provision (P.1) and type (P.2), we included the interaction between the fixed-covariates observation block (factor with two levels: pre-enrichment, during enrichment) and enrichment type (factor with 7 levels: control, furnishings, food (ground), food (suspended), scent (trail-food), scent (trail), scent (pile)).

\subsubsection{Model 2: Effect of Enrichment Type on Engagement Time and Longevity}

To model the proportion of time that individuals spent engaging with enrichment items as a function of enrichment type (P.3) and to examine the longevity of this effect (P.5), we included the interaction between the fixed covariates observation block (factor with three levels: during enrichment, post-enrichment 1, post-enrichment 2 ) and enrichment type (this time excluding the control condition).

\subsubsection{Model 3: Effect of Food- vs. Scent-Based Enrichment on Engagement Longevity}

To model the effect of food- vs. scent-based enrichment over time (i.e., to compare the longevity of each) we included the interaction between the fixed-covariates observation block (factor with three levels: during enrichment, post-enrichment 1, post-enrichment 2) and enrichment type (factor with two levels: food, scent).

\section{Results}

\subsection{Effect of Enrichment on Exploratory Behaviour}

As predicted (P.1 and P.2), the provision of enrichment increased the exploratory behaviour, and the magnitude of this increase differed significantly by enrichment type (likelihood ratio test $(\mathrm{LRT}) ; \chi^{2}(6)=16.844, p=0.001$ : Figure 1a). Post-hoc testing revealed that the food (hanging) (Tukey HSD; P = 0.008), scent (pile) (Tukey HSD; $p<0.001$ ), and scent (trail) (Tukey HSD; $p<0.0001$ ) conditions were all associated with significant increases in exploratory behaviour (Figure 1a). However, no significant differences in exploratory time were observed between the pre- and during-enrichment blocks in response to the control (Tukey HSD; $p=0.877$ ), furnish (Tukey HSD; $p=0.110$ ), food (ground) (Tukey HSD; $p=0.211$ ), or scent (trail-food) (Tukey HSD; $p=0.666$ ) conditions. Furthermore, throughout the during-enrichment block, the food (hanging), scent (pile), and scent (trail) conditions were all associated with significant increases in exploratory behaviour compared to the control conditions (Tukey HSD; $p=0.008, p=0.004, p=0.001$, respectively: Figure 1a). Species-specific responses are shown in Figure $1 \mathrm{~b}$.

\subsection{Effect of Enrichment Type on Engagement Time and Longevity}

As predicted (P.4), engagement with enrichment items diminished over time (LRT; $\chi^{2}(2)=32.667, p<0.0001$ : Figure 2a). Engagement with enrichment was significantly lower in the post-enrichment 2 block than the during- and post-enrichment 1 blocks (Tukey HSD; $p<0.001, p=0.049$, respectively: Figure 2a). However, contrary to P.3, we found no significant effect of enrichment type on engagement longevity during or after enrichment provision (i.e., engagement with enrichment diminished more or less equally over time, regardless of enrichment type (LRT; $\chi^{2}(10)=8.719, p=0.559$ : Figure 2$)$. Species-specific responses are shown in Figure 2b.

\subsection{Effect of Food- vs. Scent-Based Enrichment on Engagement Longevity}

Contrary to P.5, we found no significant difference in the longevity of engagement associated with food- vs. scent-based enrichment items (LRT; $\chi^{2}(2)=1.599, p=0.452$ : Figure 3a). Engagement with both enrichment types diminished, as described in Section 3.2 above. Species-specific responses are shown in Figure 3b. 


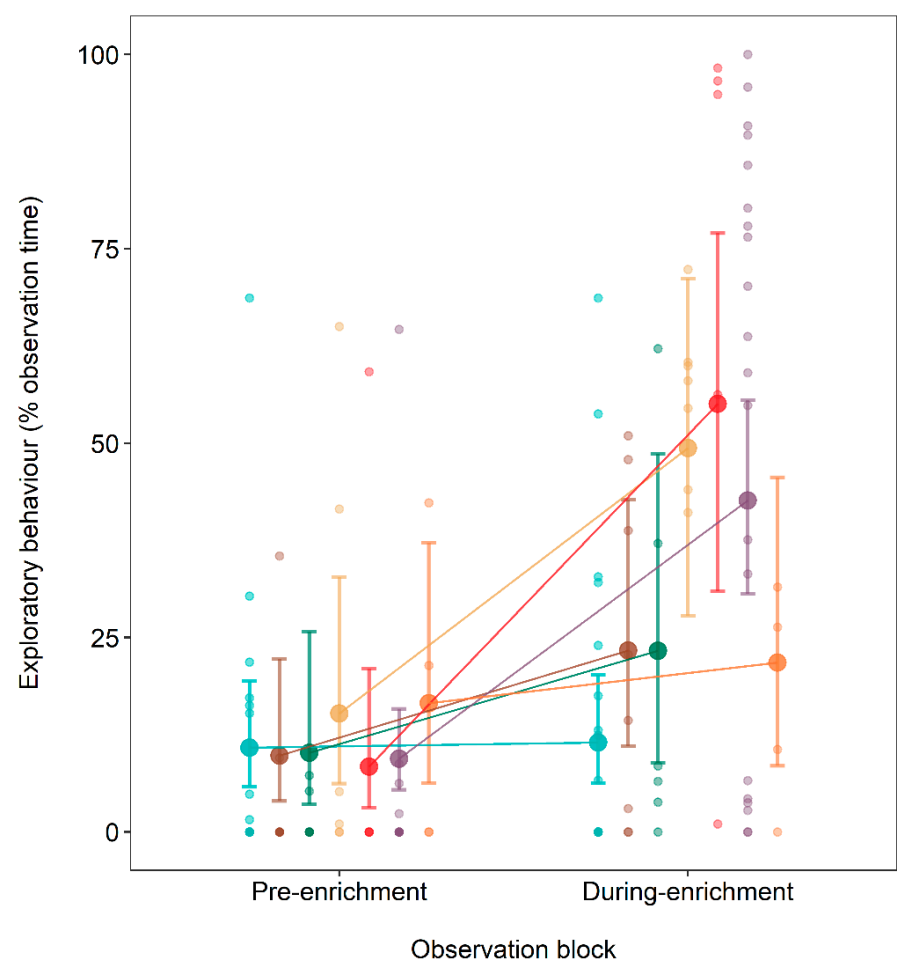
Enrichment type
- Control
- Furnish
- Food - Ground
- Food - Hanging
- Scent - Pile
- Scent - Trail
- Scent - Trail (food)

(a)

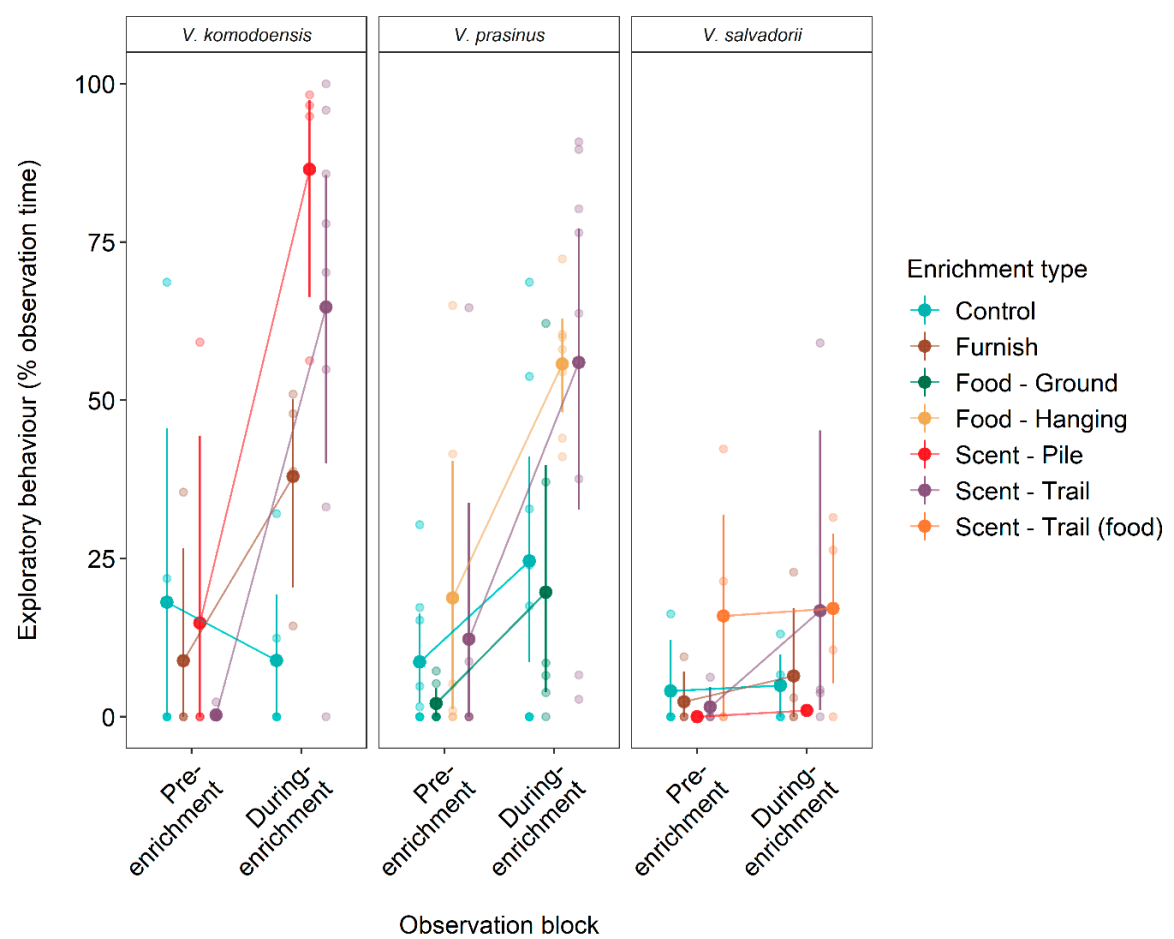

(b)

Figure 1. (a) Effect of enrichment provision on exploratory behaviour in three varanid lizard species. Large points and error bars represent predicted means \pm standard error from a Beta GLMM. Small points represent individual trials (raw data). (b) Species-specific effect of enrichment provision on exploratory behaviour in three varanid lizard species. Large points and error bars represent raw data means and $95 \%$ non-parametric bootstrap (10,000 samples) confidence intervals. Small points represent individual trials (raw data). 


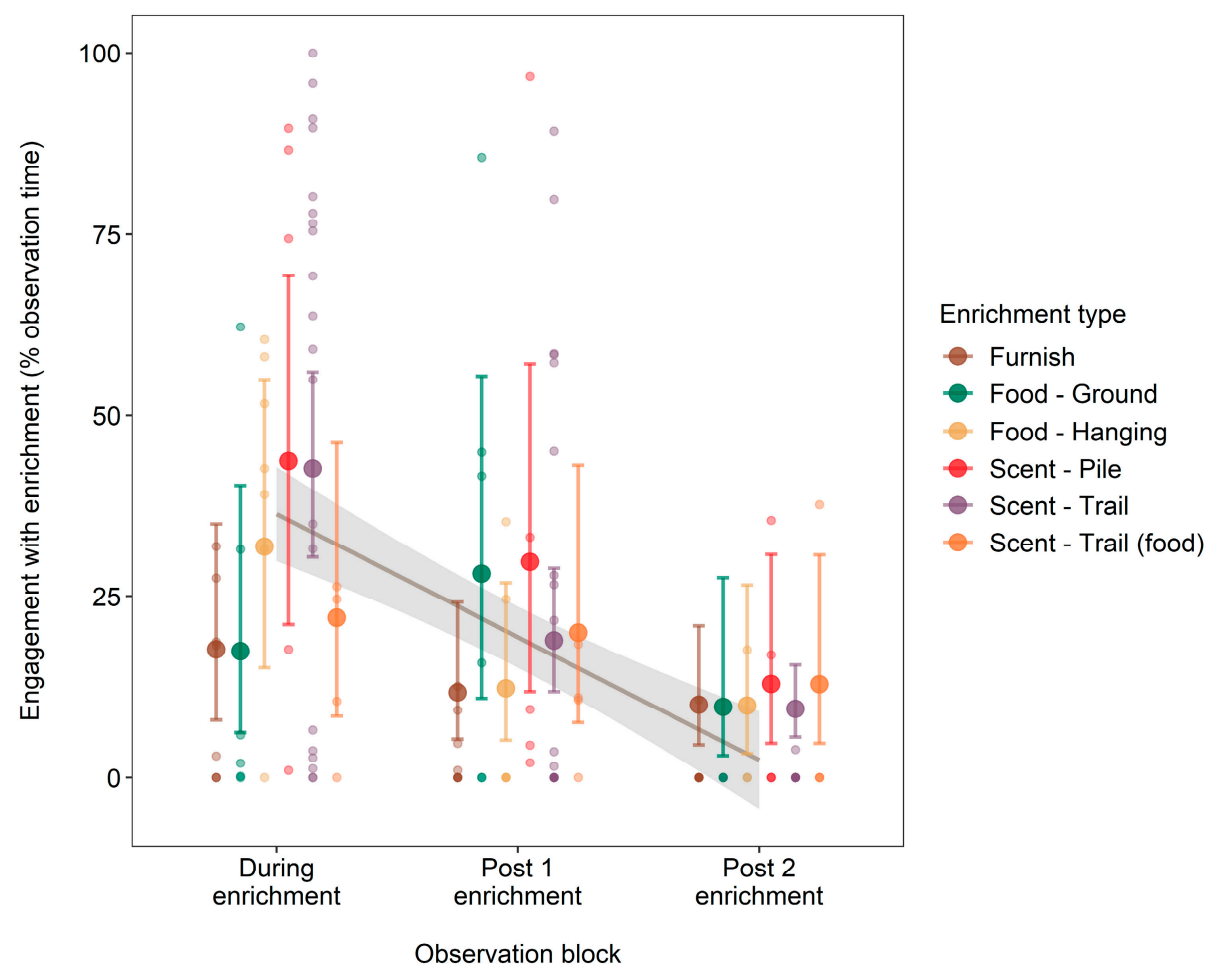

(a)

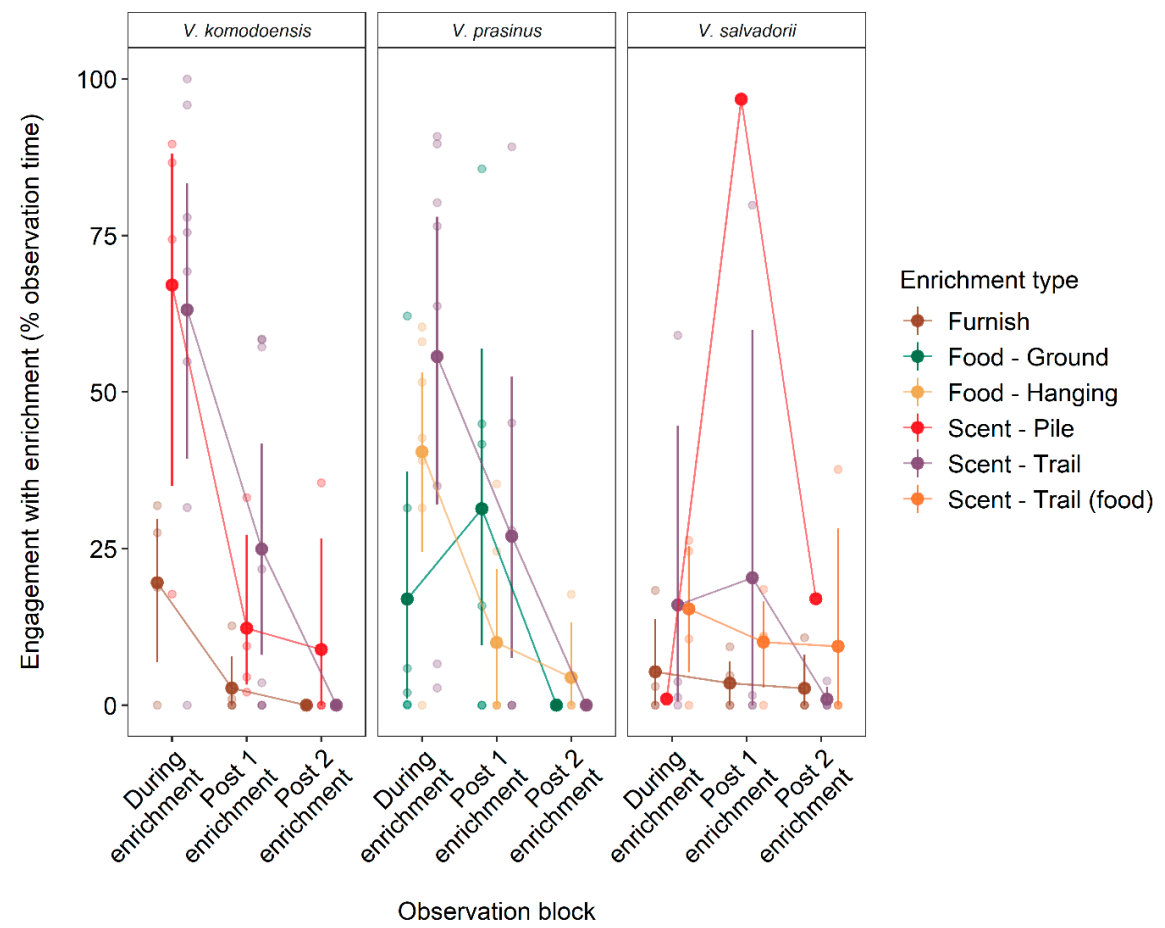

(b)

Figure 2. (a) Engagement with enrichment items over time in three varanid lizard species. Large points and error bars represent predicted means \pm standard error from a Beta GLMM. Small points represent individual trials (raw data). Line of best fit through raw data to indicate trend. (b) Speciesspecific engagement with enrichment items in three varanid lizard species. Large points and error bars represent raw data means and 95\% non-parametric bootstrap (10,000 samples) confidence intervals. Small points represent individual trials (raw data). 


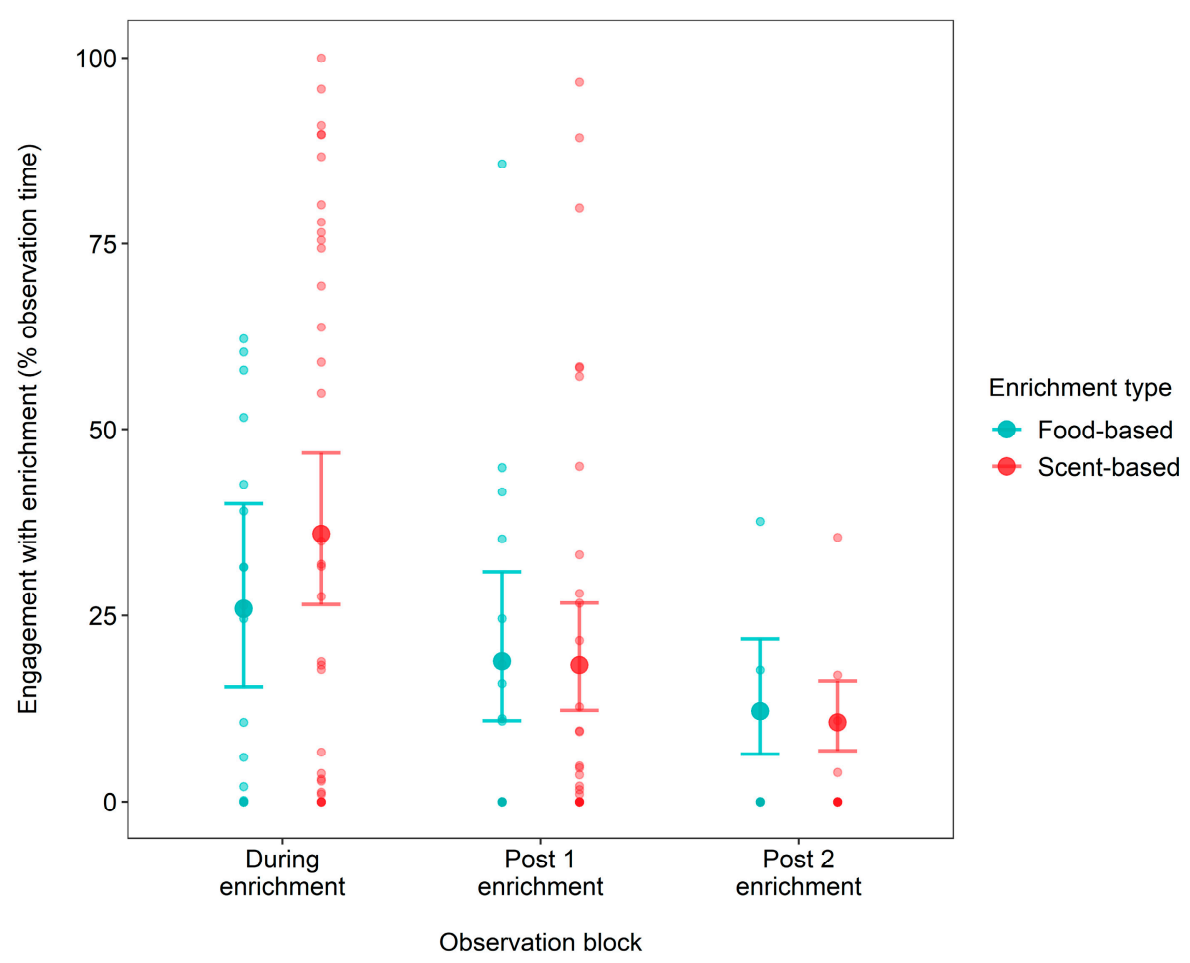

(a)

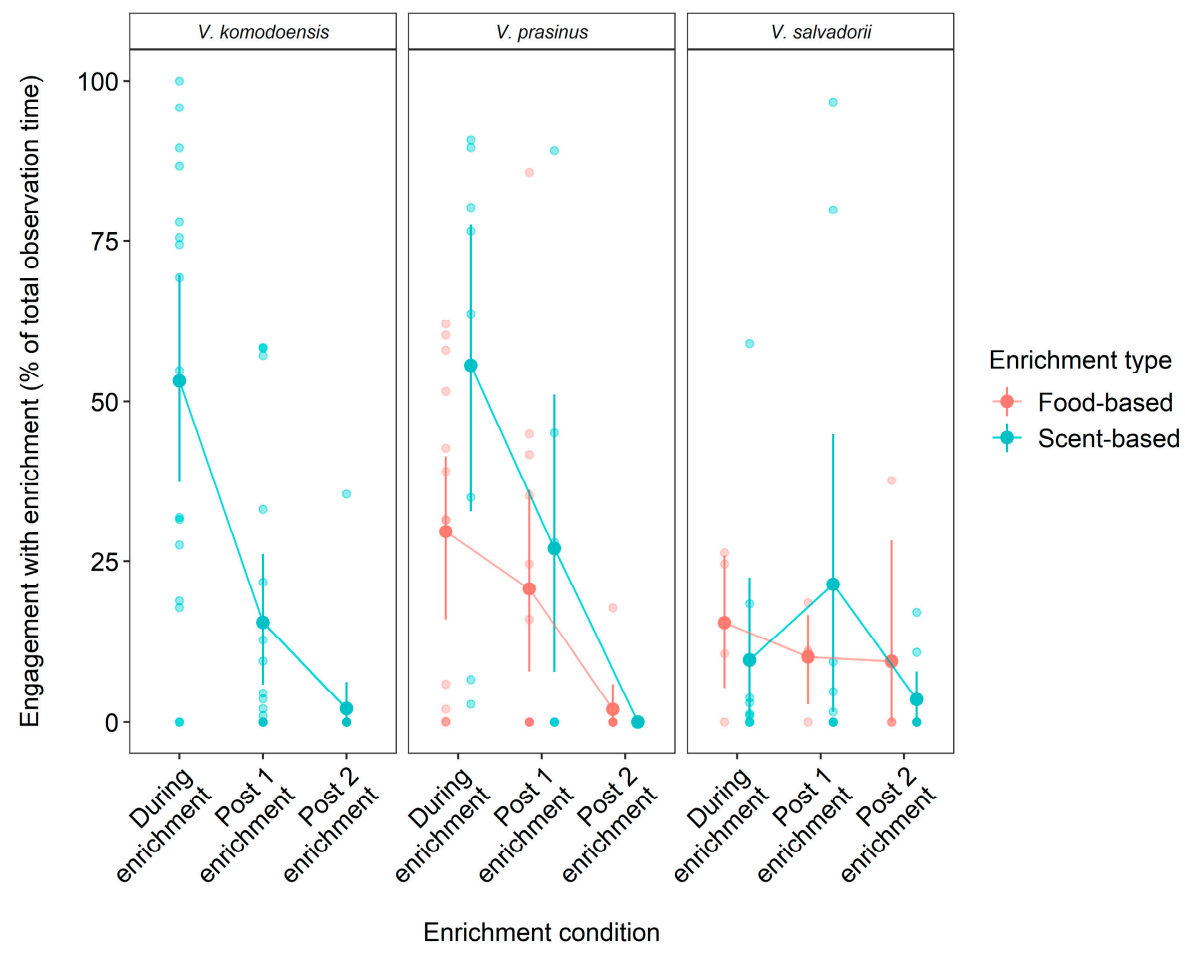

(b)

Figure 3. (a) Engagement with food- and scent-based enrichment items over time in three varanid lizard species. Error bars represent the standard error of the mean. Raw data plotted as small circles behind the main plot. (b) Species-specific engagement with food- and scent-based enrichment items in three varanid lizard species. Large points and error bars represent raw data means and 95\% non-parametric bootstrap (10,000 samples) confidence intervals. Small points represent individual trials (raw data). 


\section{Discussion}

This study examined the responses of three captive varanid lizard species to the provision of enrichment by comparing their exploratory behaviour and engagement with six different types of enrichment items and a control. Lizards exhibited significant increases in exploratory behaviour in response to hanging feeders, scent piles and scent trails. Contrary to our predictions, we found that engagement with these different enrichment types diminished more or less equally over time, returning to baseline levels by the post-enrichment 2 block (151-330 min after introduction). This finding held true when enrichment types were binned into food- and scent-based categories, i.e., no significant differences in the longevity of the enrichment effect were observed. Considered together, these results confirm that the provision of enrichment can be effective in promoting explorative behaviour and engagement in captive varanids. Specifically, our findings indicate that (a) not all enrichment types elicit similar behavioural changes, (b) that scent-based enrichment appears to provide the most effective cross-species stimulus and (c) that these effects can persist for up to $2.5 \mathrm{~h}$.

With a few exceptions $[13,14]$, there are still very few published studies about the effects of enrichment on non-avian reptiles. However, our findings contribute to, and are largely consistent with, those that exist: for example, food-based (problem tube) and scent-based (conspecific male scent) enrichment resulted in significant increases in tongue licking and exploratory activity in juvenile black-throated monitor lizards (V. albigularis albigularis) [16] and male brown wall lizards (Podarcis liolepis), [34] respectively. Similarly, a combination of sensory and physical enrichment increased the exploratory, focused swimming behaviour in sea turtles (Caretta caretta and Chelonia mydas), whilst reducing the occurrence of stereotypical behaviours [35]. The introduction of novel enrichment items was also shown to elicit play behaviour in Komodo dragons [36,37] and to facilitate training in crocodile monitors [38]; although we did not examine these behaviours in our study, our findings similarly support the provision of a complex captive environment to physically and cognitively stimulate reptiles [13].

More specifically, our results confirm that the most effective enrichment types may be those that mimic natural challenges routinely faced by lizards in the wild. Many reptiles rely primarily on chemical/olfactory senses to communicate and explore the environment $[39,40]$, and this is particularly true of varanids [41,42]. Varanids vary enormously in body size (length, including tail: $<300 \mathrm{~mm}$ to $3 \mathrm{~m}$ ) and occupy a wide range of habitats and ecological niches including terrestrial predator/scavenger ( $V$. gigantius, komodoensis), arboreal (V. prasinus, gilleni, timorensis, tristis), aquatic ( $V$. mertensi, salvator, niloticus) and small insectivore ( $V$. brevicauda) $[43,44]$. However, they are the only group of lizards that use the tongue exclusively for sensory function: unlike for all other lizards, it plays no part in food ingestion [42]. Indeed, although some debate exists, comparative studies suggest that the morphological specializations of varanid tongues (long, narrow, forked and deeply incised) relate to protrusability and sensory function [42]. Hence, the general agreement (yet to be rigorously tested) that the chemical/olfactory senses of varanids exceed those of other lizards. Komodo dragons can detect carrion from nearly $8 \mathrm{~km}$ away by virtue of airborne chemosensory signals and are reported to climb ridgelines to sniff/sample the wind for carrion odours over a large area [41]. Similarly, emerald tree monitors can detect the scent of prey hidden entirely inside tree branches [45].

Clearly, the varanid olfactory system is important in a wide range of feeding, social, territorial and courtship behaviours $[39,41-43,46]$. This may explain why the scent-based enrichment items in this study were consistently the most successful in promoting exploration and engagement, across the three varanid species: the provision of scent-based enrichment stimulates what is likely the most important, sensitive and evolutionarily conserved sensory system in this taxa $[39,47]$. With respect to food-based enrichment, it is harder to draw meaningful conclusions from this study. This is largely because $V$. prasinus was the only species to be presented with actual food-based enrichment: $V$. salvadorii was presented with a food-based scent trail, and $V$. komodoensis with only scent-based enrich- 
ment (Figure 2b). This highlights an important (solvable) shortcoming of this, and many other, captive enrichment studies, i.e., the use of unbalanced experimental designs. For example, it is important to note that our (between-species) raw data indicate a delayed response to scent-based enrichment in $V$. salvadorii, in contrast to the immediate responses of $V$. komodoensis and $V$. prasinus (Figures $2 \mathrm{~b}$ and $3 \mathrm{~b}$ ). This (potential) discrepancy may be explained by the fact that we only sampled one individual of this species and that she was 11 years old, technically considered geriatric [7]. The delayed exploratory response may simply be a result of this individual struggling/declining to move at the same speed as other younger study individuals.

Small sample sizes, low replication and unbalanced designs are common problems in zoo-based studies, including enrichment work $[8,48]$. Our study clearly suffers from these issues, and while the results should therefore be interpreted with caution, we have compensated (as far as possible) by using the appropriate statistical methods. This has allowed us to analyse the pooled responses of three similar species to an unbalanced enrichment design, whilst still accounting for the similarities and differences between individuals and species (i.e., mixed models with random effect terms). The inclusion of more individuals is rarely a simple matter in zoo-based studies; however, future studies should (and can) insist on pre-determined balanced enrichment protocols, especially if we intend to extrapolate any findings to other collections and/or species.

Here, we have shown that enrichment in the form of hanging feeders, scent piles and scent trails effectively stimulate exploratory and engagement behaviours in three captive varanid species: $V$. komodoensis, $V$. prasinus and $V$. salvadorii. We also present preliminary evidence that scent-based enrichment may be particularly effective in promoting these behaviours, alongside an ecologically valid explanation of why this may be so. Varanids are clearly complex and intelligent animals, and enrichment should be designed to physically and cognitively stimulate them in ways that mimic the natural challenges they would otherwise face in the wild. This is particularly important for the efficacy of ex situ reintroduction of threatened species, especially as more lesser-known taxa are brought into captivity as assurance populations [3]. It is also important for the wellbeing of long-term captive individuals. Finally, effective enrichment can have positively influence on visitor perception, which may in turn promote in situ projects [21]. In sum, it is essential that further enrichment studies implement robust, well-balanced protocols that monitor and evaluate the impact of a range of randomly presented enrichment items over time. In doing so, we can gather a comparable, testable body of data that will allow us to improve the wellbeing of the wide variety of reptiles in captivity.

Author Contributions: Conceptualization, G.G., A.L.F. and L.H.; methodology, R.M., G.G., M.C., A.L.F. and L.H.; formal analysis, J.O.W.; investigation, R.M.; resources, G.G. and M.C.; data curation, R.M., L.H., J.O.W.; writing-original draft preparation, J.O.W., R.M. and D.H.; writing-review and editing, R.M., A.L.F. and L.H.; visualization, J.O.W.; supervision, A.L.F. and L.H.; project administration, R.M., A.L.F. and L.H. All authors have read and agreed to the published version of the manuscript.

Funding: This research received no external funding.

Institutional Review Board Statement: This study was approved by Chester Zoo's Scientific Committee (ref 2014.39 on 17 December 2014) and conducted in accordance with Chester Zoo's Animal Research Ethics Framework. The introduction of enrichment items mentioned here is part of normal husbandry routine, and individual animals were never food- or water-deprived.

Informed Consent Statement: Not applicable.

Data Availability Statement: Data are available upon request.

Acknowledgments: Thank you to Chester Zoo's Reptile Team for their assistance throughout planning and data collection.

Conflicts of Interest: The authors declare no conflict of interest. 


\section{References}

1. Bashaw, M.J.; Gibson, M.D.; Schowe, D.M.; Kucher, A.S. Does enrichment improve reptile welfare? Leopard geckos (Eublepharis macularius) respond to five types of environmental enrichment. Appl. Anim. Behav. Sci. 2016, 184, 150-160. [CrossRef]

2. Arbuckle, K. Folklore husbandry and a philosophical model for the design of captive management regimes. Herpetol. Rev. 2013, 44, 448-452.

3. Januszczak, I.S.; Bryant, Z.; Tapley, B.; Gill, I.; Harding, L.; Michaels, C.J. Is behavioural enrichment always a success? Comparing food presentation strategies in an insectivorous lizard (Plica plica). Appl. Anim. Behav. Sci. 2016, 183, 95-103. [CrossRef]

4. Horn, H.-G.; Visser, G.J. Review of reproduction of monitor lizards Varanus spp. in captivity II. Int. Zoo Yearb. 1997, 35, 227-246. [CrossRef]

5. Horn, H.-G.; Visser, G.J. Review of reproduction of Monitor lizards Varanm spp. in captivity. Int. Zoo Yearb. 1989, 28, 140-150. [CrossRef]

6. Mendyk, R.W. Life expectancy and longevity of varanid lizards (Reptilia:Squamata:Varanidae) in North American zoos. Zoo Biol. 2015, 34, 139-152. [CrossRef]

7. Mendyk, R.W.; Newton, A.L.; Baumer, M. A Retrospective Study of Mortality in Varanid Lizards (Reptilia:Squamata:Varanidae) at the Bronx Zoo: Implications for Husbandry and Reproductive Management in Zoos. Zoo Biol. 2013, 32, 152-162. [CrossRef]

8. Burghardt, G.M. Environmental enrichment and cognitive complexity in reptiles and amphibians: Concepts, review, and implications for captive populations. Appl. Anim. Behav. Sci. 2013, 147, 286-298. [CrossRef]

9. Kuczaj, S.; Lacinak, T.; Fad, O.; Trone, M.; Solangi, M.; Ramos, J. Keeping environmental enrichment enriching. Int. J. Comp. Psychol. 2002, 15, 127-137.

10. Tarou, L.R.; Bashaw, M.J. Maximizing the effectiveness of environmental enrichment: Suggestions from the experimental analysis of behavior. Appl. Anim. Behav. Sci. 2007, 102, 189-204. [CrossRef]

11. Michaels, C.J.; Downie, J.R.; Campbell-Palmer, R. The importance of enrichment for advancing amphibian welfare and conservation goals: A review of a neglected topic. Amphib. Reptile Conserv. 2014, 8, 7-23.

12. Rosier, R.L.; Langkilde, T. Does environmental enrichment really matter? A case study using the eastern fence lizard, Sceloporus undulatus. Appl. Anim. Behav. Sci. 2011, 131, 71-76. [CrossRef]

13. Almli, L.M.; Burghardt, G.M. Environmental Enrichment Alters the Behavioral Profile of Ratsnakes (Elaphe). J. Appl. Anim. Welf. Sci. 2006, 9, 85-109. [CrossRef]

14. Burghardt, G.M.; Ward, B.; Rosscoe, R. Problem of reptile play: Environmental enrichment and play behavior in a captive Nile soft-shelled turtle, Trionyx triunguis. Zoo Biol. 1996, 15, 223-238. [CrossRef]

15. Doody, J.; Burghardt, G.; Dinets, V. Breaking the Social-Non-social Dichotomy: A Role for Reptiles in Vertebrate Social Behavior Research? Ethology 2013, 119, 95-103. [CrossRef]

16. Manrod, J.; Hartdegen, R.; Burghardt, G. Rapid solving of a problem apparatus by juvenile black-throated monitor lizards (Varanus albigularis albigularis). Anim. Cogn. 2008, 11, 267-273. [CrossRef]

17. Wilkinson, S.L. Reptile wellness management. Vet. Clin. Exot. Anim. Pract. 2015, 18, 281-304. [CrossRef]

18. Bennett, D. Monitor Lizards: Natural History, Biology \& Husbandry; Chimaira Bucnhandelsgesellschaft: Frankfurt, Germany, 1998.

19. McBrayer, L.D.; McBrayer, L.B.; Miles, D.B. (Eds.) Lizard Ecology; Cambridge University Press: Cambridge, UK, 2007.

20. Pianka, E.R.; Pianka, E.R.; Vitt, L.J. Lizards: Windows to the Evolution of Diversity; University of California Press: Berkeley, CA, USA, 2003; Volume 5.

21. Hurme, K.; Gonzalez, K.; Halvorsen, M.; Foster, B.; Moore, D.; Chepko-Sade, B.D. Environmental Enrichment for Dendrobatid Frogs. J. Appl. Anim. Welf. Sci. 2003, 6, 285-299. [CrossRef] [PubMed]

22. Young, R.J. Environmental Enrichment for Captive Animals; John Wiley \& Sons: Chichester, UK, 2013.

23. Warwick, C.; Arena, P.; Lindley, S.; Jessop, M.; Steedman, C. Assessing reptile welfare using behavioural criteria. Practice 2013, 35, 123-131. [CrossRef]

24. Whittaker, G.; Whittaker, M.; Coe, J. Prototyping Naturalistic Enrichment Features: A Case Study. In Proceedings of the Seventh International Conference on Environmental Enrichment, New York, NY, USA, 31 July-5 August 2005; p. 60.

25. Altmann, J. Observational study of behavior: Sampling methods. Behaviour 1974, 49, 227-266. [CrossRef] [PubMed]

26. Smithson, M.; Verkuilen, J. A Better Lemon Squeezer? Maximum-Likelihood Regression with BetaDistributed Dependent Variables. Psychol. Methods 2006, 11, 54. [CrossRef]

27. R Core Team. R: A Language and Environment for Statistical Computing; R Foundation for Statistical Computing: Vienna, Austria, 2021.

28. Brooks, M.E.; Kristensen, K.; van Benthem, K.J.; Magnusson, A.; Berg, C.W.; Nielsen, A.; Skaug, H.J.; Machler, M.; Bolker, B.M. glmmTMB Balances Speed and Flexibility Among Packages for Zero-inflated Generalized Linear Mixed Modeling. R J. 2017, 9 , 378-400. [CrossRef]

29. Zuur, A.F.; Ieno, E.N.; Walker, N.; Saveliev, A.A.; Smith, G.M. Mixed Effects Models and Extensions in Ecology With R; Springer: New York, NY, USA, 2009; Volume 574.

30. Douma, J.C.; Weedon, J.T. Analysing continuous proportions in ecology and evolution: A practical introduction to beta and Dirichlet regression. Methods Ecol. Evol. 2019, 10, 1412-1430. [CrossRef]

31. Sokal, R.R.; Rohlf, F.J. Introduction to Biostatistics; Dover Publications: Mineola, NY, USA, 2009. 
32. Hartig, F. DHARMa: Residual Diagnostics for Hierarchical (Multi-Level/Mixed) Regression Models. 2021. Available online: r-project.org (accessed on 31 October 2021).

33. Lenth, R.V.; Buerkner, P.; Herve, M.; Love, J.; Riebl, H.; Singmann, H. Emmeans: Estimated Marginal Means, Aka Least-Squares Means. 2021. Available online: uni-muenster.de (accessed on 31 October 2021).

34. Londoño, C.; Bartolomé, A.; Carazo, P.; Font, E. Chemosensory enrichment as a simple and effective way to improve the welfare of captive lizards. Ethology 2018, 124, 674-683. [CrossRef]

35. Therrien, C.L.; Gaster, L.; Cunningham-Smith, P.; Manire, C.A. Experimental evaluation of environmental enrichment of sea turtles. Zoo Biol. 2007, 26, 407-416. [CrossRef]

36. Burghardt, G.M. The Genesis of Animal Play: Testing the Limits; Bradford Books: Cambridge, MA, USA, 2005.

37. Murphy, J.B.; Ciofi, C.; de La Panouse, C.; Walsh, T. Komodo Dragons: Biology and Conservation; Smithsonian Institution: Washington, DC, USA, 2015.

38. Camina, Á.; Salinas, N.; Cuevas, J. Husbandry and breeding of the crocodile monitor Varanus salvadorii Peters \& Doria, 1878 in captivity. Biawak 2013, 7, 56-62.

39. Mason, R.T. Reptilian pheromones. Biol. Reptil. 1992, 18, 114-228.

40. Ord, T.J.; Martins, E.P. Tracing the origins of signal diversity in anole lizards: Phylogenetic approaches to inferring the evolution of complex behaviour. Anim. Behav. 2006, 71, 1411-1429. [CrossRef]

41. Auffenberg, W. The Behavioral Ecology of the Komodo Monitor; University Press of Florida: Gainesville, FL, USA, 1981.

42. Smith, K.K. Morphology and function of the tongue and hyoid apparatus in Varanus (varanidae, lacertilia). J. Morphol. 1986, 187, 261-287. [CrossRef] [PubMed]

43. Cogger, H. Reptiles and Amphibians of Australia; AH and AW Reed: Dunedin, New Zealand, 1975.

44. Ziegler, T.; Schmitz, A.; Koch, A.; Böhme, W. A review of the subgenus Euprepiosaurus of Varanus (Squamata: Varanidae): Morphological and molecular phylogeny, distribution and zoogeography, with an identification key for the members of the $V$. indicus and the $V$. prasinus species groups. Zootaxa 2007, 1472, e28. [CrossRef]

45. Murphy, J.; Mendyk, R.; Miller, K.; Augustine, L. Tales of Monitor Lizard Tails and Other Perspectives. Herpetol. Rev. 2019, 50, 178-201.

46. Gaalema, D. Visual Discrimination and Reversal Learning in Rough-Necked Monitor Lizards (Varanus rudicollis). J. Comp. Psychol. 2011, 125, 246-249. [CrossRef] [PubMed]

47. Pepin, D.J. Natural History of Monitor Lizards (Family Varanidae) with Evidence from Phylogeny, Ecology, Life History and Morphology; Washington University: St. Louis, MO, USA, 2011.

48. Shyne, A. Meta-analytic review of the effects of enrichment on stereotypic behavior in zoo mammals. Zoo Biol. $2006,25,317-337$. [CrossRef] 